\title{
BRAVURA INDÔMITA: ENTRE A FÁBULA E A TRAMA
}

\author{
Sharmilla O'hana Rodrigues da Silva \\ Universidade Federal do Piauí
}

\begin{abstract}
Resumo: Neste artigo, analisam-se o romance Bravura Indômita, escrito por Charles Portis e publicado em 1968, e suas duas versões para o cinema, realizadas em 1969 e em 2010. Parte-se dos conceitos de fábula e trama - também conhecidos como fábula e enredo, narração e mostração, estória e discurso - que indicam que várias narrativas podem ser criadas a partir de uma única. Usam-se os estudos desenvolvidos por Seymour Chatman, Umberto Eco, Hélio Guimarães, Linda Hutcheon, Linda Seger, Ismail Xavier, André Gaudreault e François Jost para entender como estes conceitos funcionam na relação entre literatura e cinema. Para reflexão sobre os dois filmes, recorrem-se as resenhas publicadas por Isabela Boscov, Yuri Celico, Thiago M. Correia, Marcelo Hessel, André Sollito e Rubens Ewald Filho. Percebe-se que a adaptação é um processo de reconstrução textual em que o indivíduo insere suas experiências pessoais e sociais. Logo, as duas versões fílmicas de Bravura Indômita se configuram como interpretações de diferentes leitores - neste caso, os cineastas Henry Hathaway e Joel e Ethan Coen.
\end{abstract}

Palavras-chave: Literatura. Cinema. Adaptação. Bravura Indômita.

\section{Considerações Iniciais}

Ninguém põe fé que uma menina de catorze anos possa sair de casa e viajar em pleno inverno para vingar a morte do pai, mas na época não pareceu tão estranho, embora eu deva reconhecer que isso não acontece todo dia. Eu tinha só catorze anos quando um covarde que atende pelo nome de Tom Chaney meteu uma bala em meu pai lá em Fort Smith, Arkansas, e roubou sua vida, seu cavalo e 150 dólares em dinheiro, mais duas moedas de ouro da Califórnia que ele levava em uma faixa na cintura. (PORTIS, 2011, p. 7).

Esta fala é de Mattie Ross, protagonista de Bravura Indômita, resumindo sua própria história. O romance foi escrito por Charles Portis e publicado em 1968. Neste artigo, analisaram-se as duas versões para o cinema do citado texto literário recontadas por Henry Hathaway e pelos irmãos Joel e Ethan Coen, em 1969 e em 2010, respectivamente. A partir das discussões sobre a superioridade de cada filme quando os dois são comparados, buscou-se 
a teoria que defendesse as adaptações fílmicas como textos autônomos. Chegou-se aos conceitos de fábula e trama desenvolvidos pelos formalistas russos e por outros teóricos da narrativa, com diferentes nomenclaturas: para Chatman (1978), estória e discurso, para Xavier (2003), fábula e trama - presentes no título deste artigo; para Eco (2008), fábula e enredo; para Gaudreault e Jost (2009), narração e mostração. É aqui que entra o leitor que, ao reproduzir uma história, faz-lhe de uma maneira peculiar associando suas experiências de vida e suas interpretações do contexto histórico em que vive. Sendo assim, uma mesma fábula pode ser recontada através de várias tramas.

A adaptação, enquanto processo de conversão entre mídias, implica transformações cuidadosamente pensadas, pois o cinema possui técnicas específicas para compor a narrativa como a montagem, o som e os movimentos de câmera - que influenciam não só a concepção do filme como sua recepção. Assim sendo, há a perda de alguns trechos do livro e/ ou acréscimo de outros como forma de garantir um resultado satisfatório - pelo menos, para o cineasta, pois devido a defesas exageradas da superioridade da literatura sobre o cinema, as reações a essas mudanças são, com frequência, negativas. Mesmo a adaptação é filmada a partir de um texto original - o roteiro - que equilibra fidelidade e criatividade. A literatura e o cinema são experiências diferentes e as transformações fazem palavras se confrontarem com imagens. Mais que discursos, que ganham as vozes de seus leitores, são as ações que se tornam prioridade na invenção dos Lumiére.

A teoria permeia todo este estudo, espalhando-se pelo resumo do romance que, por sua vez, está distribuído em quatro capítulos. Priorizam-se, em tal resumo, trechos presentes no livro e nos filmes - detalhes considerados irrelevantes para a ação principal foram descartados. Assim, na primeira parte, tem-se a chegada de Mattie a Fort Smith e sua atuação para reaver os bens extraídos de seu pai; na segunda, vê-se a contratação de um agente federal para capturar Chaney e a ajuda indesejada, mas necessária, de outro agente na caçada; na terceira, tem-se o desenvolvimento tanto da jornada pelas terras frias e desérticas situadas entre o Arkansas e o Texas como da relação entre os três viajantes; na última parte, vê-se o encontro de Mattie com o assassino de seu pai, iniciando tiroteios entre os homens e traçando para sempre o futuro de todos os envolvidos em tal empresa. Por fim, enfatiza-se que uma adaptação não é melhor que outra e as duas proporcionam reflexões diferentes e válidas sobre a história de Portis que Hathaway e os Coen em suas obras, doravante filme 1 e filme 2, recontam com criatividade e autonomia.

\section{A coragem de uma órfã}


Segundo Eco (2008, p. 85), foram os formalistas russos os primeiros teóricos da narratologia a formular a oposição entre fábula e enredo. A primeira se caracteriza pela organização da narrativa, da sequência das ações. O segundo se refere à ação de contar a história, adaptada ao gosto ou à necessidade de cada indivíduo. Sendo assim, o cinema ao realizar adaptações de textos literários, está recontando velhas fábulas e, ao mesmo tempo, criando novos enredos. No novo texto produzido, a estrutura semântica permanece e é reconhecida pelos leitores enquanto espectadores. Em Bravura Indômita, Mattie Ross, como se vê nas considerações iniciais, define sua fábula. Tal intertextualidade permite a incorporação de uma mesma história superficialmente ou a aproximação ao máximo de seus aspectos narrativos e até mesmo de seus diálogos. Essas fábulas, muitas vezes, não têm uma origem visível e são resultados de pequenas transformações feitas por cada indivíduo.

A primeira cena do filme 1 funciona como uma contextualização do primeiro capítulo do livro que Mattie resume em seu primeiro parágrafo. Frank se despede da família e vai, na companhia de Chaney, comprar pôneis em Fort Smith. Este, durante uma discussão, atira no pai de Mattie. O assassino rouba a vítima e foge. $\mathrm{O}$ filme 2, por sua vez, inicia com o seguinte trecho bíblico dos Provérbios: "Fogem os ímpios, sem que ninguém os persiga" citação que só aparece no livro no final do primeiro capítulo (PORTIS, 2011, p. 12). Sob a narração de uma mulher, um clarão se abre e vê-se um homem caído em frente a uma casa. Outro homem passa correndo em um cavalo.

O que os formalistas russos chamam de enredo, Xavier (2003, p. 65) denomina de trama, defendendo esta como a disposição da história para leitores e espectadores. O direito à interpretação livre permite que o cineasta proponha novos significados a determinados trechos. O teórico também critica o julgamento das adaptações através do critério da fidelidade. É possível transformar narrativas quando essas são recontadas, pois os textos originados de outros são leituras críticas e há muitos motivos para a escolha de um texto específico para a adaptação. Como explica Hutcheon (2011, p. 44-45), “[...] o propósito pode muito bem ser o de suplantar econômica e artisticamente as [adaptações] anteriores. A vontade de contestar os valores estéticos e político do texto adaptado é tão comum quanto a de prestar homenagem."

Filha e criado seguem até Fort Smith em busca do corpo do pai da garota, em um trem cheio de turistas que se deslocam para assistir um enforcamento triplo. Percebendo que a delegacia, a funerária e a pensão estão fechadas, Mattie e Yarnell decidem ir à execução também. No filme 1, os três homens que serão enforcados são vistos rapidamente e logo 
mortos; na funerária, a garota reconhece o corpo do pai, paga o caixão, o embalsamento e as despesas de envio para Yell County. No filme 2, Mattie pede ao agente funerário para passar a noite no lugar e ele diz que está esperando mais três corpos; a partir daí, surge a cena do enforcamento. Os dois filmes inserem o diálogo entre o agente funerário e Mattie: "É esse o homem? [...] Esse é meu pai. [...] Se quiser beijar, não tem problema. [...] Não, põe a tampa" (PORTIS, 2011, p. 17).

Alguns críticos de cinema afirmam que os filmes adaptados do romance de Portis ressuscitaram o gênero western ou faroeste. Segundo Ewald Filho (2011, p. 3), o Bravura Indômita de 2010 é o maior sucesso comercial da carreira dos Coen e o de Hathaway é a película a dar o único Oscar de John Wayne. Mas não são as indicações a premiações os parâmetros para o julgamento dos filmes. Cada um deles tem seus "defeitos" e "qualidades", variáveis na opinião de cada espectador. Os irmãos produziram uma nova trama porque desejavam mais fidelidade. Ora, se bem se observa, os Coen criaram mais cenas inexistentes no livro - o que talvez contraste com uma sequência totalmente inventada na obra de Hathaway. Além disso, o Bravura Indômita de 2010 é mais sombrio - muitas cenas se passam à noite - e violento - a morte física é mais explorada. Em defesa deste filme, argumenta-se:

Pulando o prólogo que o antigo possuía, este novo filme nos explica brevemente e de maneira mais soturna e sombria fatos ocorridos para que a protagonista Mattie Ross saísse à procura do covarde Tom Chaney, tendo o resto da trama praticamente igual que a do exemplar de Hathaway tinha, com mudanças aqui e ali mais significativas mesmo no epílogo, aqui sim mais desenvolvido que antes. (CELICO, 2011, p. 3-4).

No escritório do xerife, a garota descobre que Chaney está em território indígena e que, por isso, é responsabilidade dos U. S. Marshals - no filme 2, ela encontra o xerife ainda no local do enforcamento. Tanto no livro quanto em suas duas adaptações, a garota pergunta quem é o melhor agente federal e o xerife lhe dá três nomes. Ela opta por Rooster Cogburn, homem de má reputação, "um sujeito sem misericórdia, duro na queda, e medo não entra naquelas idéias. Muito chegado em puxar uma rolha" (PORTIS, 2011, p. 19), que vai transportar presos para o Tribunal Federal. Então, ela recomenda que Yarnell volte com o corpo e cuide do enterro de Frank em Yell County - no filme 2, o criado retorna da funerária. Mattie fica em Fort Smith para se vingar de Chaney e reaver cada centavo perdido pelo pai. No livro e no filme 1, ela logo procura a Pensão Monarch e se hospeda lá.

No escritório de Stonehill, o homem que vendeu os pôneis para o Sr. Ross, Mattie comenta seu intento e ele lhe pede paciência. Mas logo, é o homem quem se irrita. Ela quer devolver os pôneis que o pai comprara e uma quantia a mais pelo cavalo roubado. A 
princípio, o leiloeiro se recusa a fechar acordo com uma criança. Stonehill e a garota discutem até que ela o ameaça com um processo judicial. Ele entrega o dinheiro em troca de um documento assinado pelo advogado dela - no filme 1, o acordo já estava assinado; Hathaway também adianta, nesta cena, a segunda conversa que Mattie tem com o leiloeiro; no filme 2, como no livro, ela recebe o dinheiro do advogado e uma carta, narrada por ela e levada para Stonehill.

Como afirma Seger (2007, p. 25), "muitas adaptações bem sucedidas valeram-se do material original apenas como ponto de partida", pois os livros sempre buscam transmitir uma ideia, que é revelada, segundo a autora, a partir de questionamentos que os leitores devem levantar. Estas perguntas se resumem aos conflitos, seu início e solução, vividos pelos personagens. O filme é, portanto, uma combinação de elementos técnicos e pessoais enquanto visão de mundo, pois interessa também a motivação do diretor pela narrativa escolhida e a maneira de apresentação de tal texto. Para reafirmar ou refutar as ideias de um autor, precisa-se ler a obra deste autor.

\section{$2 \mathrm{O}$ encontro com dois agentes}

Chatman (1978, p. 9) acredita na existência de um "quê" e de um "como" referentes à narrativa. Ou seja, o primeiro ele chama de estória que é focado no interior da estrutura textual e em seus componentes - como os eventos ou a disposição dos acontecimentos, personagens e cenário; o segundo é o modo como a narrativa é transmitida. O professor estadunidense se utiliza da teoria dos estruturalistas franceses que dizem que a narrativa tem só duas partes, sendo esta distinção já feita por Aristóteles em sua Poética. Seja como for, as tramas reforçam a ideia de que narrativas são estruturas independentes de qualquer meio. A oposição entre estória e discurso é vista como a relação entre o abstrato e o concreto, pois, neste último, a existência da narrativa só ocorre através da materialização em meio físico, como por exemplo, a palavra ou a imagem.

No dia seguinte, Mattie vai ao Tribunal Federal encontrar Cogburn, que é testemunha em um caso de assassinato - no filme 1, o trecho transforma-se em duas cenas; Mattie conhece Cogburn conduzindo os presos ao tribunal, mas não consegue falar com ele; ela pergunta a um homem do seu lado quem é o agente e ele indica o homem de tapa-olho; a garota insiste em esperá-lo, mas outro homem diz que, só no dia seguinte, Cogburn vai depor e lá ela pode conversar com ele; então, a jovem vai embora. No filme 2, Mattie encontra Cogburn no banheiro de um saloon, mas ele se recusa a falar com ela; então, ela vai até o trem 
e vemos o caixão do Sr. Ross; em seguida, ela passa a noite na funerária com os corpos dos três homens enforcados; só no dia seguinte, ela vai falar com Stonehill e vai à pensão Monarch; ao subir as escadas do tribunal, Mattie escuta o início do depoimento de Cogburn. Os dois filmes apresentam trechos do interrogatório (PORTIS, 2011, p. 34-46).

Mattie espera na saída do tribunal, aproxima-se de Cogburn e o ajuda a enrolar um cigarro. Ela expõe seu problema, o desejo de capturar Chaney e mostra a arma do seu pai. Faminto, ele a convida para conversarem em seu quartinho, que fica no fundo da mercearia de Lee, um japonês. Após o jantar, em meio a um jogo de cartas, o federal planeja primeiro a captura de Lucky Ned Pepper, ladrão e líder do bando que Chaney acompanha, mas para isso cobra um valor alto e eles não chegam a um acordo. Na pensão, Mattie conhece um novo hóspede. LaBoeuf assemelha-se a um "cowboy do velho-oeste" e desperta certa atração. Ele sabe o motivo da presença de Mattie em Fort Smith e mostra à garota uma fotografia na qual ela reconhece Chaney - seu nome verdadeiro é Theron Chelmsford. Antes de matar o pai de Mattie, o assassino cometeu o mesmo crime contra um senador em outro estado. Então, LaBoeuf se apresenta como sargento do Texas Rangers, contratado pela família do político. Ele tenta fazer um acordo com a garota, mas ela não aceita: o criminoso precisa ser punido no Arkansas. Mattie se mostra arredia e discute com o homem. Os dois filmes também apresentam trechos literais do livro (PORTIS, 2011, p. 57-61).

Em seu artigo, Boscov (2011, p. 130-131) elogia as duas adaptações, afirmando que foi o filme com John Wayne - e não o livro em si - que imortalizou os personagens. Mas tais atuações, que para a crítica de cinema já eram perfeitas e harmônicas, seriam novamente repetidas sob o temor de reconstruir uma trama tão boa quanto a primeira. As opiniões, obviamente, dividem-se quanto a vários aspectos, dentre os quais: a caracterização de seus protagonistas, interpretados por Wayne e Bridges - dois atores excelentes; o tom visual das palavras de Portis - em Hathaway, há mais o cômico, enquanto nos Coen é a brutalidade que se prioriza. Muitos entendem que a fábula enfatiza a relação de afeto desenvolvida ao longo da caçada ao assassino e os filmes transmitem tal mensagem. Apesar da fatalidade que os une, Cogburn, Mattie e LaBoeuf demonstram sensibilidade e até mesmo sabedoria acumuladas em suas sofridas experiências pessoais. São personagens com personalidades opostas e, ao mesmo tempo, similares que concordam em uma única obssessão: “[a] ideia de retidão e de distribuição justa de direitos e deveres" (BOSCOV, 2011, p. 131).

No dia seguinte, Mattie e Cogburn retomam o acordo e só depois de uma longa discussão, com desaforos para cada lado e a ameaça de procurar outro agente, ele permite a companhia da garota, que volta à estrebaria e decide ficar com um dos pôneis. Ela o chama de 
Little Blackie e ele logo é montado. No filme 2, Mattie enfatiza que é patroa de Cogburn e, já montando Little Blackie, ela pergunta ao agente quando ele estará pronto para partir. Ainda sonolento, ele planeja a captura do ladrão. Ele faz o serviço por cem dólares e ela não contesta o valor. O homem diz que inicia a caçada no dia seguinte e permite que ela vá. Ao chegar à mercearia, no dia marcado, Mattie encontra Cogburn e LaBoeuf conversando. A oferta do texano tem mais vantagens: o governo do estado oferece US\$ 500 por Chaney vivo e a família do senador oferece US\$1.500 - nos filmes, as cenas seguem como no livro (PORTIS, 2011, p. 77-82).

LaBoeuf quer Chaney no Texas, Mattie quer o mesmo homem no Arkansas. Logo, os homens combinam a viagem sem a garota que exige de Cogburn a parte do dinheiro já paga, mas ele já gastou. Então, ela sai furiosa da casa e, apesar de não querer o ranger por perto, prepara-se toda a noite para a viagem. Ela os segue a uma curta distância até ser percebida. Expulsa da balsa, Mattie atravessa o rio com o cavalo espera os homens na outra margem. Após reclamações do companheiro, Cogburn permite que a pequena participe da caçada e os três iniciam sua jornada - no filme 2, ao chegar na mercearia, a garota descobre que Cogburn já saiu e lhe deixa uma passagem de trem para Yell County e um bilhete. Quando chega ao rio, avista Cogburn e LaBoeuf já do outro lado.

Para Hutcheon (2011, p. 22), “a arte deriva de outra arte; histórias nascem de outras histórias" e as adaptações surgem como respostas de um leitor apaixonado que reafirmam sua posição quanto ao texto lido, pois diferentes leitores abordam também diferentes aspectos da narrativa que geram variadas interpretações - no caso dos filmes analisados aqui, a diferença está nos detalhes, nos trechos que não afetam a ação principal. O cineasta, assim como o escritor, é um contador de histórias que está sempre à procura de maneiras criativas e significativas de apresentar suas narrativas. É na intertextualidade que ele produz obras originais. Este processo infinito de recriação torna Bravura Indômita, o livro e os filmes, textos fontes para outras manifestações artísticas.

\section{A caçada de um assassino}

Hessel (2011, p. 1) também apoia a ideia de que o romance de Portis só foi realmente aproveitado pelos Coen. É que, enquanto filme, o Bravura Indômita de Hathaway pertence a um gênero - o western crítico - que, na década de 1960, já estava consolidado e, no processo de tranformá-lo em clássico, o cineasta teria perdido a oportunidade de discutir o mito do cowboy. Ao mesmo tempo, o crítico considera essencial a relação entre Mattie e Cogburn, 
sendo a garota uma espécie de símbolo do pós-feminismo, muito mais agressiva que a jovem da primeira versão. Correia (2011, p. 1), por sua vez, explica a aplicação do estilo dos Coen em Mattie, que se caracteriza como a interpretação deles sobre a personagem: como uma heroína típica, a adolescente busca a justiça de modo que a captura de Chaney não é motivada por vingança. A necessidade dela de conduzir o assassino para julgamento no Arkansas revelaria outro tema do filme: a noção de lugar. Tanto Mattie quanto LaBoeuf estão sempre reafirmando de onde são, o que demonstra forma diferentes da aplicação das leis em cada estado.

Eles atravessam a Nação Cherokee e LaBoeuf, cumprindo a promessa que fizera horas antes, dá uma surra em Mattie. Cogburn só consegue pará-lo quando saca sua arma. A cena é literal nos dois filmes (PORTIS, 2011, p. 91-92). Mattie está determinada a sofrer cansaço, fome e frio e a não se queixar de qualquer dificuldade. Em seguida, eles encontram um pequeno comércio e comem. Mais uma vez, atravessam um rio e recebem a notícia de que Lucky Ned Pepper fora visto nas proximidades. À noite, Cogburn e LaBoeuf discutem inicialmente, pela dificuldade de encontrar água em regiões desérticas; depois, pela importância de suas unidades policiais. A neve toma conta do lugar e eles retornam, com dificuldade, para sua missão. À procura de um abrigo, eles avistam uma pequena casa e, desconfiados, os dois agentes resolvem cercá-la. Assim, acontece no filme 1.

No filme 2, as informações do homem do comércio são parafraseadas por Cogburn e LaBoeuf que, junto com a garota, descansam ao redor de uma fogueira, no alto de uma colina. Mas, é nesta cena que Cogburn se mostra interessado na recompensa informada por LaBoeuf, querendo levar Chaney para o Texas. O marshal e a garota discordam quanto ao combinado feito antes e depois ele discute com o ranger. LaBoeuf diz a Mattie que Cogburn é golpista e acompanhava dois assassinos. O federal se aborrece e anula o acordo com o texano. LaBoeuf vai embora e Mattie fica preocupada. Ela segue viagem com Cogburn. Nesta sequência, eles retornam à mercearia para obter novas informações. Em seguida, apenas Cogburn e Mattie cercam a tal casa.

Alguns encaram o filme dos Coen como uma refilmagem, tão digna quanto à primeira versão cinematográfica do romance de Portis. Sabemos que as expectativas dos leitores são muitas e, geralmente, as adaptações de textos literários nas telas do cinema são negativamente comentadas. Daí, pensa-se na ansiedade da realização de um remake de uma obra muito conhecida. Para Sollito $(2011$, p. 2), "poucos diretores estão à altura do desafio", no qual os irmãos cineastas resolveram arriscar. O crítico também diz que o filme 2 é mais fiel ao texto original, mas não se concorda - há um equilíbrio do romance de Portis nos dois 
filmes; os cineastas valorizam os mesmos trechos - talvez a entonação das falas, as expressões faciais dos personagens e, principalmente, a visão do espectador do século XXI, dêem impressões erradas sobre a versão de 1969. Dentre os aspectos divergentes, há a ênfase nas atuações dos personagens Mattie e Cogburn - exageradas em suas personalidades - e a caracterização da caçada como sombria - muitas das cenas de Hathaway são realizadas sob a luz do sol. A resenha é concluída sem afirmar a superioridade de qualquer um dos filmes. O tom e as atuações de 2010 se igualam ao romantismo e ao heroísmo da primeira adaptação.

Dois ladrões, conhecidos por Cogburn, estão dentro da casa. Há um tiroteio e um dos bandidos é baleado. Quincy e Moon são revistados, desarmados e algemados. Pressionado pelo novo risco da prisão e pela possibilidade de ter uma perna amputada, Moon decide contar o que sabe, mas ele e Quincy discutem e se matam. Lucky Ned Pepper e outros bandidos devem aparecer na casa. No bolso de Quincy, Cogburn encontra uma moeda de ouro - no filme 2, a moeda estava com o homem da mercearia. É do pai de Mattie. O marshal e o ranger planejam uma emboscada para os "visitantes" e a garota também quer participar, mas é impedida - no filme 2, ele relata isso a garota antes de encontrarem Quincy e Moon e, neste momento, LaBoeuf retorna.

Os bandidos finalmente aparecem. São seis e estão desconfiados da tranquilidade ao redor da casa. Eles atiram para cima e, como resposta, LaBoeuf dispara seu rifle. Logo, Cogburn atinge dois ladrões e Mattie fica assustada. Os que vivem, conseguem fugir, mas não se sabe se Chaney está com o grupo. Cogburn culpa o ranger texano pela falha e ambos iniciam uma discussão (PORTIS, 2011, p. 125-126). Cogburn tem um novo plano: receber algum dinheiro pelos bandidos mortos e envolver mais agentes na perseguição dos outros. Mattie cuida do ferimento no braço de LaBoeuf - no filme 1, ele leva um tiro na mão. No filme 2, LaBoeuf está sozinho na cabana quando os bandidos aparecem; eles o amarram e Cogburn inicia o tiroteio; os homens discutem porque o ranger acredita que o tiro que levou foi disparado por Cogburn; este, bêbado, nega, eliminando a ideia de que não trabalha mais como antes.

Eles chegam em um pequeno povoado na Nação Choctaw com os corpos dos bandidos. LaBoeuf vai à procura de um jovem índio que é médico para que este cuide de seu ferimento. Mattie e Cogburn procuram Boots Finch, o oficial de polícia da área. Este se encarrega de enterrar os quatro bandidos mortos. Um longo acordo é feito entre Cogburn e Finch com relação ao destino do dinheiro recuperado no assalto. No armazém, os três têm uma farta refeição. A esposa do Sr. McAlester oferece a cama para Mattie, mas a garota recusa com medo de que Cogburn e LaBoeuf propositalmente partam sem ela. No filme 2, os 
viajantes não levam os corpos dos bandidos mortos e não atravessam nenhum povoado. Quando mais uma vez, LaBoeuf e Cogburn discutem, eles desistem da caçada e o texano vai embora.

Aqui, encaixam-se as seguintes palavras: “[...] a questão central não é a história em si, mas o modo como o filme tece a narrativa e nos traz os dados que nos permitem tomar consciência do que se trata" (XAVIER, 2003, p. 66), pois na adaptação o visível é a trama e é só com ela que se pode relacionar e deduzir a fábula. Antes de tudo, narrar é dispor um relato, sequenciá-lo de várias formas. Já Guimarães (2003, p. 92-93) diz que a adaptação “[...] pode gerar uma cadeia quase infinita de outros textos, constituindo um fenômeno cultural que envolve processos dinâmicos de transferência, tradução e interpretação de significados e valores histórico-culturais."

\section{Encarando o perigo}

Gaudreault e Jost (2009, p. 40) dão aos mesmos conceitos aqui defendidos os nomes de narração e mostração. $\mathrm{O}$ argumento dos dois teóricos tem origem na mimesis de Platão, associando à trama a representação teatral. Logo, nesta perspectiva, as duas versões fílmicas de Bravura Indômita são mostrações que encenam a ação principal de uma fábula, que é o romance de Portis. A adaptação sugere que a intertextualidade pode ser uma referência consciente ou não. De qualquer forma, cada sociedade tem uma produção cultural que se renova constantemente influenciando o momento presente. Essa harmonia de contextos é feita por cada indivíduo quando fala, escreve ou se expressa de outras formas. Sendo o cinema uma maneira de também contar histórias, pequenas modificações são logo percebidas em seu discurso.

Oitenta quilômetros depois, Cogburn e LaBoeuf descansam e Mattie procura água para o banho. A garota escuta um barulho e, do outro lado do regato, vê Chaney. A jovem fica em estado de choque e quando ele a reconhece, ela lhe aponta o revólver e diz que vai levá-lo para Fort Smith. Diante da recusa de ir com a garota e de um movimento brusco, Mattie atira e atinge o homem na barriga. Mas, logo sua arma falha e, dessa vez, ela é atacada por Chaney. Cogburn, LaBoeuf e os comparsas de Chaney correm para a margem do riacho e outro tiroteio se inicia. Lucky Ned Pepper ameaça matar Mattie e a faz de refém, enquanto propõe um acordo a Cogburn (PORTIS, 2011, p. 151). Em uma caverna, Chaney é tratado de seu ferimento e a garota conta sua história para Lucky Ned Pepper. Em seguida, ela avista os 
agentes federais ao longe e fica desolada enquanto eles vão embora - no filme 2, Cogburn vai embora sozinho.

Diante do cumprimento do acordo, Lucky Ned Pepper ordena que Chaney fique com a garota e a abandone no lugar combinado. Já sozinha com o assassino de seu pai, ela põe água para ferver e joga a mesma no criminoso, mas não consegue fugir. Com uma pancada na cabeça, Mattie desmaia (PORTIS, 2011, p. 165) - isso não ocorre nos filmes. Logo depois, ela ouve a voz de LaBoeuf - no filme 2, ele também aparece neste momento. Ele rende o bandido, mas logo Lucky Ned Pepper e seu bando reaparecem. Cogburn bloqueia a passagem e mais um tiroteio começa. O agente é ferido no rosto e nos ombros - no filme 1, Mattie é resgatada por LaBoeuf quando ainda está sozinha com Chaney. Eles fogem e só em seguida é que o bando de Ned se encontra com Cogburn, que depois mata Chaney.

LaBoeuf mata Lucky Ned Pepper, mas é atingido por uma pedra arremessada por Chaney. Rapidamente, Mattie atira na cabeça do tal bandido. Com o impacto do tiro, ela é arremessada para trás e cai em um poço. Mattie quebra o braço e grita por LaBoeuf, mas não tem resposta. A cada minuto, a garota afunda mais na lama. Ela tenta se manter otimista apesar da situação não lhe favorecer. Dentro do buraco, Mattie se depara com um cadáver. O medo da garota se concretiza e um ninho de cobras também é avistado. Um homem aparece no alto. É Chaney que logo é atingido novamente por Cogburn. Seu corpo também cai no poço. Uma cobra morde a mão de Mattie. Cogburn desce com uma corda, mas não consegue subir com a jovem. Depois que ele suga o veneno da mordida de Mattie, ele a amarra na corda e LaBoeuf puxa os dois com a ajuda de Little Blackie - no filme 1, Mattie não quebra a mão e Cogburn cuida da mordida da cobra quando eles já estão fora do buraco. No filme 2 é o próprio agente que aparece no topo do buraco, pois Chaney já está morto.

O leitor cria um mundo imaginário que se transforma também quando ele age como diretor, mas não é somente um processo de conversão de palavras em imagens, pois as adaptações permitem o diálogo entre diferentes contextos sociais e questionam "[...] a apropriação e ressignificação de produtos culturais do passado [...], projetando-os para diferentes públicos e atribuindo-lhes novas significações e sentidos" (GUIMARÃES, 2003, p. 110-111). Na fábula, a causalidade seria o detalhe que diferencia o discurso de cada indivíduo. Sem a ordenação própria do aspecto temporal, o indivíduo se distancia da história e até mesmo ultrapassa seus limites - o que influencia na interpretação de um texto literário para o cinema, por exemplo. Dentre as análises de Bravura Indômita, as que se intitulam psicológicas são as mais polêmicas. Hessel (2011, p. 2-13), por exemplo, foi criticado negativamente ao dizer que quando Cogburn chupa o veneno da picada de Mattie, ele 
simbolicamente a beija e ela se apaixona, encerrando a relação deles como sexual e não paterna como outros acreditam.

Cogburn leva Mattie a um médico e o texano fica no local. A caminho de Fort Smith, eles são carregados pelo pônei que já demonstra cansaço. Quando o animal ameaça diminuir sua velocidade, o agente lhe golpeia com o punhal, mas o cavalo não aguenta e morre - isso ocorre apenas no filme 2. Daí para frente, Cogburn carrega Mattie. O ferimento se agrava e a menina tem o braço amputado. A mãe dela e o Dr. Dagget presenciam a cena (PORTIS, 2011, p. 181). Sob o efeito de morfina e sedativos, Mattie descobre que as balas no rosto de Cogburn foram retiradas e que o próprio LaBoeuf desceu, machucado, para resgatar o corpo de Chaney que foi levado para o Texas - no filme 1, LaBoeuf morre após resgatar seus companheiros no poço e o cavalo Little Blackie é deixado para trás quando cai de cansaço.

Um fato preocupa Mattie: Cogburn é acusado de irresponsabilidade por permitir que ela os acompanhasse na caçada. Ao saber que o agente salvara a vida da garota, o Dr. Daggett lhe pede desculpas pessoalmente e faz o restante do pagamento. Mattie escreve para Cogburn, pedindo que ele vá visitá-la, mas ele dá uma desculpa que não a convence (PORTIS, 2011, p. 182). A família Ross nunca consegue reaver o cavalo e a moeda de ouro que foram de Frank e nunca mais tem a oportunidade de ver Cogburn novamente. Anos depois, em um recorte de jornal, Mattie descobre Cogburn participando de um espetáculo circense onde mostrava suas habilidades com armas e decide procurá-lo (PORTIS, 2011, p. 185). No circo, ela descobre que ele falecera dias antes aos 68 anos de idade e que ninguém apareceu para reclamar o corpo. Ela leva o corpo de Cogburn para Yell County e o enterra no jazigo da família Ross. De LaBoeuf, ela nunca mais teve notícias.

No filme 1, Cogburn leva Mattie para a casa dela em Yell County; ele conta a ela que levou o corpo de LaBoeuf para ser enterrado no Texas e que foi buscar a recompensa prometida pela captura de Chaney; ela lhe mostra a lápide do pai e expressa o desejo de ver o agente enterrado lá também; ele aceita e ela lhe dá a arma que foi de Frank; eles se despedem e ele vai embora. No filme 2, após a cena em que é carregada por Cogburn até um médico, há uma passagem de tempo - como no livro. 25 anos depois, Mattie vai ao circo, narrando que Cogburn nunca voltou para receber o restante do pagamento, e na última cena enterra o corpo do oficial em Yell County.

O interesse na maneira como a história é contada permite a defesa da tese de que as modificações na transformação de uma linguagem em outra são compreensíveis. Cada leitor imagina um modo para explicitar sua compreensão do texto lido. É necessário então que o cineasta se concentre na fábula pretendida e crie seu enredo a partir dela. Não há, então, “[...] 
uma leitura 'única' e 'correta' para o texto literário, cabendo ao adaptador descobrir o verdadeiro sentido do texto e transferi-lo para uma nova linguagem e um novo veículo" (GUIMARÃES, 2003, p. 94-95).

\section{Considerações Finais}

Percebe-se, através desta pesquisa, que a adaptação é um processo de reconstrução textual em que o indivíduo insere suas interpretações e experiências. Logo, as duas versões fílmicas de Bravura Indômita se configuram como leituras de diferentes leitores - neste caso, os cineastas Henry Hathaway e Joel e Ethan Coen. As transformações feitas por eles do romance de Charles Portis, a supressão e o acréscimo de alguns trechos, não afetam a mensagem da ação principal. Esta, por sua vez, conhecida como fábula, narração e história, é resumida pela própria protagonista, Mattie Ross, no parágrafo que introduz a obra. A partir daí, o que se vê é o esforço daqueles envolvidos na realização das duas películas em produzir novas tramas, enredos, mostrações e discursos, que sejam significativos enquanto obras autônomas e obras adaptadas. Apresentaram-se os trechos considerados mais importantes para os cineastas, partindo dos aspectos em comum e dos que são divergentes nos textos analisados.

Dentre os trechos do livro mantidos nos filmes, ainda que com diferentes perspectivas, tem-se: um resumo do motivo da saída de Frank Ross; a ida de Mattie e Yarnell a Fort Smith para trazer de volta o corpo do pai morto da garota; o enforcamento dos três homens; a ida a agencia funerária e à pensão; a conversa com o xerife e com o leiloeiro da cidade; a procura por Rooster Cogburn e o interrogatório deste no tribunal; a discussão com LaBoeuf; a caracterização do espaço e dos personagens; o encontro dos três no rio em que eles atravessam de balsa e ela, a cavalo; a surra que o texas ranger dá na garota; o cerco à cabana de Quincy e Moon e os tiroteios; o encontro de Mattie e Chaney e o sequestro dela pelo bando de Lucky Ned Pepper; a queda da adolescente no poço.

Dentre os trechos do livro subtraídos dos filmes estão: a visão do interior do trem no qual Yarnell é vítima de preconceito e Mattie o defende, já demonstrando o seu senso de justiça; a exaltação do lugar de modo generalizado - não há só a comparação entre cidades, mas também entre estados e para a garota, o Arkansas é melhor que todos os outros - o que talvez explique o desejo dela de ver Chaney punido lá; mais momentos em que Mattie expressa sua fragilidade - no enforcamento, ela chora; personagens de participação reduzida, como Yarnell, a Sra. Floyd, Lee, Dr. Dagget e a família Ross e a inexistência de Boots Finch 
e do Sr. McAlester no filme 2; a narrativa paralela de Odus Wharton, bandido e inimigo de Cogburn; o braço quebrado de Mattie devido à queda no poço; as correspondências da jovem para o agente e a vida adulta dela, 25 anos depois dos acontecimentos, no filme 1.

Dentre as cenas totalmente inventadas, o filme 1 traz: Cogburn conduzindo presos ao tribunal federal no capítulo 2; uma parada para o descanso na qual Mattie vê as guloseimas trazidas por Cogburn no capítulo 5; a caça de LaBoeuf a um peru no capítulo 6; a parada de Cogburn para beber onde ele demonstra embriaguez no capítulo 8; a morte de LaBoeuf no capítulo 11 e a sequência final presente nos capítulos 12 e 13 após a visita de Dr. Daggett. No filme 2, vêem-se: o encontro de Mattie e Cogburn no banheiro do saloon e o pedido da garota para dormir na agência funerária no capítulo 4; a narração dela de uma carta para a mãe explicando o motivo sua presença em Fort Smith no capítulo 14; as partidas de LaBoeuf após discussões com Cogburn nos capítulos 18, 31 e 32; a descoberta de um corpo morto pendurado em uma árvore no meio do caminho nos capítulos 19 a 21; a aparição de um homem coberto com pele de urso que indica, para os dois viajantes, a cabana onde estão Quincy e Moon no capítulo 22; a entrada de uma caverna vazia nos capítulos 29 e 30; e a segunda discussão entre os homens quando Cogburn diz que LaBoeuf só atrapalha, demite-se e manda Mattie embora nos capítulos 31 e 32.

Por fim, acredita-se que as artes não se repelem, mas se completam e que a proximidade entre elas contribui na reprodução e na reconstrução de significados. Qualquer manifestação humana, oral ou escrita, verbal ou não-verbal, faz parte de um infinito processo intertextual. Com o cinema não é diferente, apesar de sua relação com a literatura ser mais íntima e de mútuo proveito. Os autores utilizados neste trabalho sugerem a importância de um estudo acerca do tema que dá aos filmes a oportunidade de defesa. Ainda que produtos de fábulas reconhecidas e assimiladas, eles são obras autônomas e originais, de linguagens diferentes, que comunicam de formas diferentes. Partiu-se da (re)descoberta de dois tipos de narrativa feitas pelos formalistas russos, permeando tal teoria com o resumo da história em si. São muitas, então, as possibilidades de interpretação de um texto que permitem ao indivíduo o uso de sua criatividade.

\section{Referências}

BOSCOV, Isabela. “Áspero e lindo". Revista Veja, 2011, edição 2203, ano 44, n. 6, p. 130131, 09 fev. 2011. 
BRAVURA Indômita. Direção: Henry Hathaway. Roteiro: Marguerite Roberts. Produção: Hall B. Wallis. Intérpretes: John Wayne; Kim Darby; Glen Campbell e outros. Paramount Pictures. EUA, 1969. 1 DVD (129 min), son, color.

BRAVURA Indômita. Direção e roteiro: Joel Coen \& Ethan Coen. Produção: Joel Coen; Ethan Coen e Scott Rudin. Intérpretes: Jeff Bridges; Hailee Steinfield; Matt Damon e outros. Paramount Pictures. EUA, 2010. 1 DVD (110 min), son, color.

CHATMAN, Seymour. "Preface". In: Story and discourse: narrative structure in fiction and film. Ithaca, Nova York: Cornell University Press, 1978. p. 9-12.

CHATMAN, Seymour. "Elements of narrative". In: Story and discourse: narrative structure in fiction and film. Ithaca, Nova York: Cornell University Press, 1978. p. 19-22.

CELICO, Yuri. “Bravura Indômita 1969 X 2010”. Blog Classe de Cinema. 27 fev. 2011. Disponível em: <http://classedecinema.blogspot.com.br/2011/02/bravura-indomita-1969-x2010.html>. Acesso em: 23 mar. 2012.

CORREIA, Thiago Macêdo. "Bravura Indômita". Cineplayers. 09 fev. 2011. Críticas.

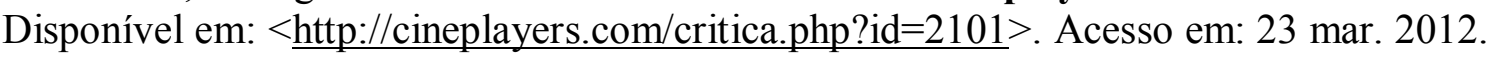

ECO, Umberto. "As estruturas narrativas". In: Lector in fabula: a cooperação interpretativa nos textos narrativos. Tradução de Attílio Cancian. São Paulo: Perspectiva, 2008. p. 85-92. (Estudos).

EWALD FILHO, Rubens. "Revisitando Bravura Indômita de 1969”. Portal R7. 07 fev. 2011. Blog do Rubens Ewald Filho. Disponível em: $<$ http://noticias.r7.com/blogs/rubens-ewaldfilho/2011/02/07/revisitando-bravura-indomita-de-1969/>. Acesso em: 23 mar. 2012.

GAUDREAULT, André; JOST, François. "Cinema e narrativa". In: A narrativa cinematográfica. Tradução de Adalberto Müller, Ciro Inácio Marcondes e Rita Jover Faleiros. Brasília: EDUNB, 2009. p. 31-53.

GUIMARÃES, Hélio. "O romance do século XIX na televisão: observações sobre a adaptação de Os Maias". In: PELLEGRINI, Tânia. et. al. Literatura, cinema e televisão. São Paulo: SENAC/ Itaú Cultural, 2003. p. 91-114.

HESSEL, Marcelo. "Bravura Indômita: Crítica”. Omelete. 10 fev. 2011. Cinema. Disponível em: <http://omelete.uol.com.br/cinema/bravura-indomita-critica/>. Acesso em: 23. Mar. 2011.

HUTCHEON, Linda. "Começando a teorizar a adaptação: O quê? Quem? Por quê? Como? Onde? Quando?" In: Uma teoria da adaptação. Tradução de André Cechinel. Florianopólis: EDUFSC, 2011. p. 21-59.

PORTIS, Charles. Bravura Indômita. Tradução de Cássio de Arantes Leite. Rio de Janeiro: Alfaguara, 2011. 
SEGER, Linda. "Como transformar fatos e ficção em filme". In:

adaptação: como transformar fatos e ficção em filme. Tradução de Andrea Netto Mariz. São Paulo: Bossa Nova, 2007. p. 17-27.

SOLLITO, André. "Recriando um clássico". Revista Época. 03 fev. 2011. Mente Aberta. Disponível em: <http://revistaepoca.globo.com/Revista/Epoca/0,EMI208469-15220,00RECRIANDO+UM+CLASSICO.html>. Acesso em: 23 mar. 2012.

XAVIER, Ismail. "Do texto ao filme: a trama, a cena e a construção do olhar no cinema". In: PELLEGRINI, Tânia et. al. Literatura, cinema e televisão. São Paulo: SENAC/ Itaú Cultural, 2003. p. 61-89.

[Recebido em março de 2012 e aceito para publicação em junho de 2012]

\title{
True Grit: between fábula and trama
}

\begin{abstract}
In this research, it is analyzed the novel True Grit, written by Charles Portis and published in 1968, and its film adaptations, made in 1969 and 2010. It is started from the fábula and trama concepts - also known as fábula and enredo, narração and mostração, estória and discurso - that indicate several narratives can be created from an only one. It is used the studies developed by Seymour Chatman, Umberto Eco, Hélio Guimarães, Linda Hutcheon, Linda Seger, Ismail Xavier, André Gaudreault and François Jost to understand how these concepts work in the literature and cinema relationship. For reflection about the two films, it is resorted to the reviews published by Isabela Boscov, Yuri Celico, Thiago M. Correia, Marcelo Hessel, André Sollito and Rubens Ewald Filho. It is perceived the adaptation is a process of textual reconstruction in which the individual inserts his/ her personal and social experiences. So, the two film versions of True Grit are characterized as interpretations of different readers - in this case, the filmmakers Henry Hathaway and Joel and Ethan Coen.
\end{abstract}

Keywords: Literature. Cinema. Adaptation. True Grit.

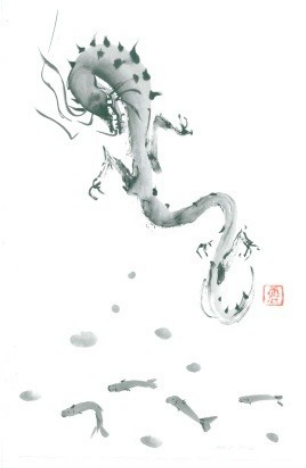

